\title{
Dietary resource partitioning among age-sex classes of Agama agama (Squamata: Agamidae) assessed by fecal pellet analysis
}

\author{
Safianu Rabiu \\ Department of Biological Sciences, Bayero University Kano. 1 Gwarzo Road, PMB 3011, Kano 700241, Nigeria. \\ E-mail: srabiu.bio@buk.edu.ng.
}

\begin{abstract}
Dietary resource partitioning among age-sex classes of Agama agama (Squamata: Agamidae) assessed by fecal pellet analysis. Dietary analysis is critical to understand the ecological roles of lizards, especially of species of Agama that are colonizing continents and islands from which they were previously absent. The foraging habits of four groups-viz., adult females, adult males, and young and juveniles (of both sexes)—of Agama agama in Nigeria were observed to assess the diet of the lizards and the contribution of the diet to separating age-sex classes. The claim that flying arthropods are less likely to be eaten by lizards was tested, and the hypothesis of dietary opportunism was explored. Sets (3-5 pellets) of 1453 fecal pellets collected during a 2-yr period were linked to individual lizards. Multivariate discriminant analysis of individual food items showed $61 \%$ lizards were correctly classified to age-sex. However, items pooled into composite food groups, yielded fewer (43\%) correctly classified lizards. Cluster Analysis indicated that individual foods were less common $(46.3 \%)$ to lizard classes than composite foods $(76.1 \%)$. Thus, lizard age-sex classes are better differentiated when prey item is identified at the lowest possible taxonomic level. Overall, arthropods are the largest, composite food for all lizard classes but, the relative amounts of different arthropod taxa varies significantly, and is highest for Diptera. Other foods include plants, seeds, and non-arthropod animal material. Differing coefficients of variation accentuate dietary disparities within classes. Proportions of most individual and composite diet items differ significantly by month, season, and study site. Although consumed by lizards, no traces of white mold were found in the feces; this underscores the value of combining fecal analysis with surveillance of foraging habits of Agama agama.
\end{abstract}

Keywords: diet, lizards, Nigeria, savannah, season, West Africa.

\section{Resumo}

Partilha de recursos alimentares entre classes de idade-sexo em Agama agama (Squamata: Agamidae) avaliada por análise de pelotas fecais. A análise da dieta é crítica para a compreensão

Received 06 September 2018

Accepted 28 February 2019

Distributed June 2019 
dos papéis ecológicos dos lagartos, especialmente das espécies de Agama que estão colonizando continentes e ilhas dos quais tenham estado previamente ausentes. Os hábitos de forrageio de quatro grupos—fêmeas adultas, machos adultos e jovens e juvenis (de ambos os sexos)—de Agama agama da Nigéria foram estudados para avaliar a dieta dos lagartos e a contribuição da dieta na separação de classes idade-sexo. Foi testada a afirmação de que artrópodes voadores têm menor probabilidade de ser ingeridos pelos lagartos, e foi explorada a hipótese do oportunismo alimentar. Grupos (3-5 pelotas) de 1.453 pelotas fecais coletadas durante um período de 2 anos foram relacionados a lagartos individuais. Uma análise discriminante multivariada dos itens alimentares individuais mostrou que $61 \%$ dos lagartos estavam clasiificados corretamente em idade-sexo. Contudo, itens reunidos em grupos alimentares compostos mostraram uma classificação idade-sexo correta reduzida (43\%). A análise de agrupamento indicou que os itens individuais foram menos comuns (46.3\%) para as classes de lagartos do que os itens compostos (76.1\%). Assim, as classes idade-sexo dos lagartos são melhor distinguidas quando o item é identificado até o menor nível taxonômico possível. De modo gerla, artrópodes são o maior grupo composto para todas as classes de lagartos, mas o número relativo dos diferentes táxons de artrópodes varia significativamente e é maior para Diptera. Outros itens alimentares incluem plantas, sementes, e material animal não-artrópode. Coeficientes de variação diferentes acentuam disparidades de dieta dentro das classes. As proporções da maioria dos itens individuais e compostos diferem significativamente por ano, estação e local de estudo. Embora consumido pelos lagartos, nenhum resquício de fungo branco foi encontrado nas fezes; isso diminui o valor da análise fecal combinada com a vigilância dos hábitos de forrageio de Agama agama.

Palavras-chave: dieta, estação, lagartos, Nigéria, Oeste africano, savana.

\section{Introduction}

The speciose lizard genus Agama (Daudin, 1802) is widely distributed throughout West Africa (Leaché et al. 2006, Gonçalves et al. 2012, Mediannikov et al. 2012, Kissling et al. 2016, Leaché et al. 2017). Species of Agama often colonize areas outside their natural African distribution-e. g., Santo Antão Island of the Cape Verde Archipelago (Vasconcelos et al. 2014); subtropical parts of Florida in the U.S. (Enge et al. 2004); and the island of Madagascar (Wagner et al. 2009). Apart from pets and livestock, Agama agama (Linnaeus, 1758) may be one of the most conspicuous animals in northern Nigeria.

Agama agama has been characterized as omnivorous, eating caterpillars, beetles, spiders, ants, berries, seeds, and flowers (Marshall and Hooks 1960, Pauwels et al. 2004). In Nigeria, the lizard also feeds on plant material (Chapman and Chapman 1964). In a subcontinental study of a wide West African transect, Akani et al. (2013) concluded that Agama is mainly insectivorous. Harris (1964) reported that arthropods represented $100 \%$ of the food for the species. Gupta (1982) noted heavy consumption of non-flying arthropods in Agama from eastern Nigeria but, because mosquitoes and house flies are winged, he attributed their low contribution to the diet of Agama agama to their ability to fly and avoid predation. The lizard has also been described as opportunistic and a generalist, readily able to switch its diet to utilize whatever food is available at a particular locality-i.e., insects, small vertebrates (including cannibalism), flowers, and fruits (Barnett and Emms 2005, Hardy and Crnkovic 2006, Wagner et al. 2009, Vasconcelos et al. 2014). Delsinne et al. (2015) reported the first documented observations of Agama agama feeding on hostile army ants, Dorylus (Anomma) congolensis Santschi, 1910; it is the only reptile known to do so. Moreover, another species of Agama has been reported to 
consume native lizard species in the islands of the Cape Verde Archipelago (Vasconcelos et al. 2014). Both cannibalism and depredation of small vertebrates and nestlings of birds have been reported by local residents in the vicinity of the sites of the present work.

Several descriptions of the diets of lizards, amphibians, and small mammals are based on examination of stomach contents or entire digestive tracts of necropsied field-caught animals (Rabiu and Rose 1997, Luiselli et al. 2011, Lopes et al. 2017) and from stomachs of dead animals (Angelici et al. 1997). Other studies (e.g., Angelici et al. 1997, Pérez-Mellado et al. 2011) are based on examination of lizard fecal matter collected in the field. Direct observation of foraging also has been used to study food selection (e.g., Avery 1971, Sáez and Traveset 1995); however, Angelici et al. (1997) think that diets determined by examination of fecal matter should be supplemented with other methods from the same lizard population.

A fundamental ecological question is the level at which analysis of fecal or stomach material will discriminate age-sex classes of Agama agama on the basis of dietary differences and provide information about other diet-related interactions. Some studies (e.g., Hardy and Crnkovic 2006) have attempted to identify food fragments to species. In contrast, other studies that identify dietary items to a composite group (i.e., composed of pooled, like-items; e.g., phylum level) are carried out fairly quickly but do not help separate age-sex classes or inform on food resource partitioning.

The goal of this study is to characterize the diet of Agama agama in the semi-arid region of northern Nigeria by examination of fecal pellets, and determine the taxonomic level of identification of fecal contents that best differentiates age-sex classes of lizards. The claim that winged arthropods can avoid some predation by Agama agama was tested, along with the hypothesis that the tendencies toward dietary opportunism will be apparent in analyses of fecal pellets.

\section{Materials and Methods}

\section{Study Area}

Two study sites are west of the city of Kano,

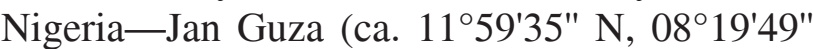
E; 479.75 m a.s.1.) and Rijiyar Zaki (ca. 11 ${ }^{\circ} 58^{\prime} 59^{\prime \prime}$ $\mathrm{N} ; 08^{\circ} 23^{\prime} 18^{\prime \prime} \mathrm{E} ; 467.25 \mathrm{~m}$ a.s.1.). The other two sites are east of the city in the towns of Gezawa (ca. $12^{\circ} 05^{\prime} 26^{\prime \prime} \mathrm{N}, 08^{\circ} 45^{\prime} 48^{\prime \prime} \mathrm{E}$; $448.36 \mathrm{~m}$ a.s.1.) and Zakirai (ca. 12 ${ }^{\circ} 05^{\prime} 27^{\prime \prime} \mathrm{N}, 08^{\circ} 53^{\prime} 13^{\prime \prime}$ E; $410.87 \mathrm{~m}$ a.s.l.). In the $1960 \mathrm{~s}$ the general study area represented a healthy balance of moderate human population density, in combination with traditional, peasant agriculture, relatively sizable patches of reserved land, and effective landmanagement practices, including fallow system. However, in the last 40 years, the area has been subject to an overwhelming human population explosion, over-cultivation, lawlessness, and near absence of any rural and forest management authority; thus, the natural fields have given way to ravaged savannah, which is steadily deteriorating into arid wasteland. Coincident with this degradation, the diversity of arthropods, the main food of lizards, has decreased. There are scattered indigenous trees and a groundcover of herbs and grasses dominated by weeds. The trees include: Tamarindus indica L., Parkia biglobosa (Jacq.) R. Br. ex G. Don (being rapidly decimated); Albizia chevalier Harms; Parinari macrophylla Sabine; Ficus lutea Vahl; Sclerocarya birrea (A. Rich.) Hochst.; and Acacia albida Delile.

The Jan Guza site had a few established homes, frequent human activity, and rain-fed farming from June-October. Crops included corn, Sorghum bicolor (L.) Moench; ground nuts, Arachis hypogaea L.; and occasional water melon, Citrullus lanatus (Thunb.) Matsum. and Nakai. The Rijiyar Zaki site (3.5 ha, 4 km E Jan Guza) was made up of undeveloped suburban plots. Both sites at Gezawa (2.95 ha) and Zakirai (3.05 ha), $30 \mathrm{~km}$ and $44 \mathrm{~km}$ east of Rijiyar Zaki, respectively, are at the outer limits of the townships. There were a few exotic trees and native shrubs 
scattered amongst dormant construction projects. Annual grass and herb vegetation was not as rich as at the two previously mentioned sites. The dominant arthropod taxa at each site consisted of Diptera, Hymenoptera, Blattodea (Suborder Isoptera, termites) and Orthoptera.

\section{Fecal Analysis}

Fecal pellets were collected by hand, from each lizard encountered, in walking surveys conducted for 5 days each month when any five adult individual lizards of either sex, and a mixed sex of five young and juveniles were observed. Three to five fecal pellets were collected from the each individual lizard observed. When fecal pellets could not be associated with an individual lizard, I watched a while longer or sought a substitute of the same class. In total, fecal materials from about 15 lizards from each site were collected each month, resulting in a total 1453 fecal sample sets with at least 483 for each age-sex class.

The pellets were prepared for quantitative estimates by protocols similar to those of López et al. (1991), Pérez-Mellado and Corti (1993), and Rabiu and Rose (1997). The contents were washed with warm, distilled water and thoroughly homogenized. A dissecting scope or scanner objective of a light microscope was used for a preliminary examination, which sometimes would yield whole seeds and poorly digested insects. From each set of fecal matter, five small portions of the homogenate were added to five separate slides, spread evenly, and covered with a cover slip. Using a $10 \times 10$ squares ocular grid fitted into a microscope (at $100 \times$ magnification), five randomly selected visual fields were examined.

Food fragments were classified as follows: arthropods and identified to order; fragmentary or whole undigested seeds, including monocots, dicots and melon; dicots (leaves and buds); and monocots (leaves and buds). Non-arthropod animal materials that included leathery fragments, probably of soft egg origin, and remains of animal fibers were recorded. Some unidentifiable arthropod material also was recorded. Sand particles were ignored. Individual dietary items were combined into four composite categories-viz., arthropods, seeds, leaves and buds, and non-arthropod animal material.

The frequencies and relative mean percentages of individual and composite diet items were calculated in area of the visual field (excluding clay or sand particles) with the formula used in Rabiu and Rose (1997): $\overline{\mathrm{a}}=\sum(I a) / T \times 100$, in which $\overline{\mathrm{a}}$ is the mean contribution of food $A$ to the diet in a particular period; $I$ is the percentage of a sample that was identifiable; $a$ is the percentage contribution of food $A$ to the identifiable fraction of that sample; and $T=\sum\left[\sum(I a)\right]$ is the total of all food types in the sample.

Percentage values were arcsin square-root transformed prior to statistical evaluations. Most statistical evaluations were done with Minitab 18 LLC. Tests were two-tailed with alpha set at 5\%, but better $P$ values are reported as well. Multivariate Discriminant Analysis and Cluster Analysis were used to determine the effect of particular food items on the age-sex classification of lizards made in casual field surveillance. GLM Model ANOVA (because of some unequal representation of items in the feces) was used to check the effects of age-sex classes, seasons, site, and year on mean composition of individual diet items, and from $\mathrm{R}^{2}$-adjusted values, the degree to which they could explain the variances. The effects of age-sex classes (adult female, adult male, and young and juvenile); months (June 2015-May 2017); seasons (dry vs. rainy); year (2015, 2016, and 2017); and sites (JanGuza, Rijiyar Zaki, Gezawa, and Zakirai) on the composite fecal contents of the lizards were tested with a five-factor MANOVA.

\section{Results}

Of the total of 1453 sets of fecal pellets from as many lizards, 1412 had fragments of dipteran prey for a frequency of $97.17 \%$. In decreasing order of frequency were black ants, Blattodea 
(Suborder Isoptera, termites), and yellow ants. Each of two other groups-Orthopterans and hymenopterans (i.e., bees and wasps)-was represented in nearly $30 \%$ of the samples. Melon seeds had highest frequency of all seeds and some arthropod orders. Amongst the composite foods, arthropods were the most frequent, with seeds following with occurrences in 541 (37\%) of the lizards.

\section{Dietary Contribution to Age-Sex Class Separation}

In a Multivariate Discriminant Analysis of composite fecal diet items, 621 of 1453 lizards were correctly classified-i.e., fewer than $50 \%$ (Table 1). However, when individual diet items were used in the statistical run, $874(60.2 \%)$ of 1453 samples correctly classified to age-sex class; the values were $0.518,0.614$, and 0.672 , for the adult females, adult males, and young and juveniles, respectively (Table 2). Minitab does not compare tests of significance for multivariate procedures.

In another multivariate statistical run-Cluster Analysis of composite food groups-76.11\% of all foods were common to all 1453 lizards. In the same statistical run for 22 individual diet items, the commonality of diet shrank to $46.26 \%$. Both

Table 1. Multivariate discriminant analysis of Agama agama age-sex classes (adult females, adult males, and young and juveniles) versus composite diet items determined from analysis of 1453 sets of fecal pellets from June 2015-May 2017 at four sites near Kano, Nigeria.

\begin{tabular}{lccc}
\hline $\begin{array}{l}\text { Response } \\
\text { predictors }\end{array}$ & \multicolumn{3}{c}{$\begin{array}{c}\text { Lizard (males, females, and young and juveniles) } \\
\text { Composite foods: arthropods, leaves and buds, seeds, non-arthropod animal materials }\end{array}$} \\
\hline & \multicolumn{4}{c}{$\begin{array}{c}\text { Summary of classification with cross-validation } \\
\text { Put into group }\end{array}$} & Adult female & Adult male & Young and juvenile \\
\hline Adult female & 94 & 71 & 79 \\
Adult male & 114 & 177 & 56 \\
Young and juvenile & 237 & 350 & 350 \\
Total N & 483 & 485 & 485 \\
N correct & 94 & 177 & 350 \\
Proportion & 0.195 & 0.365 & 0.722
\end{tabular}

Overall: $N=1453, N$ Correct $=621$, Proportion correct $=0.427$

\begin{tabular}{lccc}
\hline & \multicolumn{3}{c}{ Squared distance between groups } \\
\cline { 2 - 4 } & Adult female & Adult male & Young and juvenile \\
\hline Adult female & 0.000 & 0.222 & 0.121 \\
Adult male & 0.222 & 0.000 & 0.505 \\
Young and Juvenile & 0.121 & 0.505 & 0.000 \\
\hline
\end{tabular}

Linear discriminant function for groups

\begin{tabular}{lccc}
\cline { 2 - 4 } & Adult female & Adult male & Young and juvenile \\
\hline Constant & -169.41 & -161.61 & -171.06 \\
Arthropods & 3.41 & 3.33 & 3.43 \\
Leaves and buds & 3.43 & 3.32 & 3.43 \\
Seeds & 3.37 & 3.30 & 3.37 \\
\hline
\end{tabular}


multivariate statistic analyses indicated that lizards were better differentiated into age-sex classes by prey taxa that were identified at lower taxonomic levels as individual dietary items, rather than at the level of composite foods.

\section{Food Composition: Individual Food Items}

All age-sex classes of Agama agama consumed more dipteran insects than any other prey item. Mean consumption of dipterans in the young and juveniles is $40.8 \%$, and somewhat less in adult females and adult males at $28.5 \%$ and $23.2 \%$, respectively. The coefficient of variations are within the same range (42-56; Table 3). There is less age-sex class uniformity in the consumption of hymenopteran (black ants) as indicated by the greater disparity in the coefficient of variation - a value of 71 for adult female and young and juveniles, and 104 for adult male lizards; thus, there is more variability among adult male lizards. Intraclass variability in the consumption of termites and cockroaches (Blattodea) is higher in adult females and young and juveniles, than in adult males. Other cases where lizard classes showed large differences in coefficient of variation included, Dictyoptera (mantids), flowers, egg material, and Coleoptera.

Table 2. Multivariate discriminant analysis of $A$. agama age-sex lizard classes (adult females, adult males, and young and juveniles) versus individual diet items determined from analysis of 1453 sets of fecal pellets from June 2015-May 2017 at four sites near Kano, Nigeria.

\begin{tabular}{|c|c|c|c|}
\hline \multirow[t]{3}{*}{$\begin{array}{l}\text { Response } \\
\text { predictors }\end{array}$} & \multicolumn{3}{|c|}{$\begin{array}{c}\text { Lizards (adult males, adult females and young and juveniles) } \\
\text { Total of } 22 \text { individual dietary items }\end{array}$} \\
\hline & \multicolumn{3}{|c|}{ Summary of classification with cross-validation } \\
\hline & Adult female & Adult male & Young and juvenile \\
\hline Adult female & 250 & 122 & 132 \\
\hline Adult male & 94 & 298 & 27 \\
\hline Young and juvenile & 139 & 65 & 326 \\
\hline Total N & 483 & 485 & 485 \\
\hline$N$ correct & 250 & 298 & 326 \\
\hline Proportion & 0.518 & 0.614 & 0.672 \\
\hline
\end{tabular}

Overall: $N=1453 ; N$ Correct $=874 ;$ Proportion Correct $=0.602$

\begin{tabular}{lccc}
\hline & & \multicolumn{2}{c}{ Squared Distance Between Groups } \\
\cline { 2 - 3 } & Adult Female & Adult Male & Young and Juvenile \\
\hline Adult female & 0.00000 & 1.61332 & 0.77229 \\
Adult male & 1.61332 & 0.00000 & 3.14242 \\
Young and juvenile & 0.77229 & 3.14242 & 0.00000 \\
\hline
\end{tabular}

Discriminant Function for some selected food items

\begin{tabular}{lccc}
\cline { 2 - 3 } & Adult Female & Adult Male & Young and Juveniles \\
\hline Constant & -180.82 & -172.83 & -182.59 \\
Hymenoptera (black ants) & 3.66 & 3.55 & 3.67 \\
Hymenoptera (yellow ants) & 3.69 & 3.62 & 3.68 \\
Diptera & 3.63 & 3.54 & 3.67 \\
Blattodea & 3.58 & 3.51 & 3.61 \\
\hline
\end{tabular}


Table 3. Overall mean percent, standard error of mean (SE), and coefficient of variation (CoefVar) for some selected individual prey identified at lower taxonomic levels, and composite diet items determined from analysis of 1453 sets of fecal pellets of Agama agama collected from June 2015-May 2017 at four sites near Kano, Nigeria.

\begin{tabular}{|c|c|c|c|c|c|}
\hline Food/Prey Item & Lizard Class & $N$ & $\%$ Mean & $S E$ & CoefVar \\
\hline \multirow{3}{*}{$\begin{array}{l}\text { Hymenoptera } \\
\text { (black ants) }\end{array}$} & Adult female & 483 & 21.55 & 0.701 & 71.46 \\
\hline & Adult male & 485 & 14.05 & 0.665 & 104.23 \\
\hline & Young and juveniles & 485 & 21.48 & 0.696 & 71.35 \\
\hline \multirow[t]{3}{*}{ Diptera } & Adult female & 483 & 28.50 & 0.738 & 56.93 \\
\hline & Adult male & 485 & 23.18 & 0.796 & 75.65 \\
\hline & Young and juveniles & 485 & 40.79 & 0.791 & 42.72 \\
\hline \multirow[t]{3}{*}{ Blattodea } & Adult female & 483 & 5.97 & 0.379 & 139.36 \\
\hline & Adult male & 485 & 4.30 & 0.338 & 172.89 \\
\hline & Young and juveniles & 485 & 5.53 & 0.353 & 140.49 \\
\hline \multirow[t]{3}{*}{ Orthorptera } & Adult female & 483 & 4.81 & 0.358 & 163.63 \\
\hline & Adult male & 485 & 7.06 & 0.487 & 152.01 \\
\hline & Young and juveniles & 485 & 3.73 & 0.337 & 198.52 \\
\hline \multirow{3}{*}{$\begin{array}{l}\text { Lepidoptera } \\
\text { (larvae) }\end{array}$} & Adult female & 483 & 2.14 & 0.232 & 237.11 \\
\hline & Adult male & 485 & 1.60 & 0.222 & 303.79 \\
\hline & Young and juveniles & 485 & 2.01 & 0.226 & 247.12 \\
\hline \multirow[t]{3}{*}{ Coleoptera } & Adult female & 483 & 3.43 & 0.369 & 236.26 \\
\hline & Adult male & 485 & 4.96 & 0.472 & 209.77 \\
\hline & Young and juveniles & 485 & 1.24 & 0.213 & 376.90 \\
\hline \multicolumn{6}{|l|}{ Composite Foods } \\
\hline \multirow[t]{3}{*}{ Arthropods } & Adult female & 483 & 87.87 & 0.67 & 0.67 \\
\hline & Adult male & 483 & 84.32 & 0.81 & 0.81 \\
\hline & Young and juveniles & 483 & 92.97 & 0.50 & 0.50 \\
\hline \multirow[t]{3}{*}{ Leaves and buds } & Adult female & 483 & 2.03 & 0.22 & 0.22 \\
\hline & Adult male & 483 & 1.41 & 0.19 & 0.19 \\
\hline & Young and juveniles & 483 & 1.77 & 0.24 & 0.24 \\
\hline \multirow[t]{3}{*}{ Seeds } & Adult female & 483 & 9.51 & 0.62 & 0.62 \\
\hline & Adult male & 483 & 11.39 & 0.73 & 0.73 \\
\hline & Young and juveniles & 483 & 5.09 & 0.44 & 0.44 \\
\hline \multirow{3}{*}{$\begin{array}{l}\text { Non-arthropod } \\
\text { animal material }\end{array}$} & Adult female & 483 & 0.57 & 0.16 & 0.16 \\
\hline & Adult male & 483 & 2.87 & 0.38 & 0.38 \\
\hline & Young and juveniles & 483 & 0.15 & 0.09 & 0.09 \\
\hline
\end{tabular}




\section{Food Composition: Composite Food Items}

More than $84 \%$ of the food consumed by each of the three age-sex classes of Agama agama consists of arthropods. Adult male lizards consumed less leaves and buds and flowers than either of the two other age-sex classes, and ate more non-arthropod animal material and leathery material (probably reptilian eggs). Animal material usually is seen in feces collected between June and early November (i.e., rainy season). Non-arthropod animal material was absent from feces from December-February of both 2016 and 2017. This seasonal contrast is statistically significant (GLM ANOVA, nonarthropod animal material versus seasons; $F_{l}=$ 26.89; $p<0.05)$. The information on relative class share of diets taken in different seasons at the four sites is given in Figure 1.

\section{Percent Composite Dietary Share by Age-Sex Classes, Sites, and Seasons}

All lizard classes have about the same mean composite (for all sites) proportional amounts of arthropod foods (higher in dry season: female, 89.13\%; males, 85.05\%; young and juveniles, $93.67 \%$ ), and consistently, all age-sex classes consumed more arthropods in the dry season than in the wet season. In contrast, all age-sex classes ate more plant material during the rainy season than in the dry season (Figure 1). Both females, and young and juveniles consumed more leaves and buds than did males. For each lizard class, more seeds were eaten in the dry season than in the wet season, and adult males ate proportionally more $(12.7 \%)$ seeds than females $(9.1 \%)$; the adults ate more seeds than the young and juveniles $(5.8 \%)$. In all seasons, adult males consumed proportionally the most $(80 \%)$ diet share of nonarthropod animal material (Figure 1).

\section{Statistical Evaluations}

The composition of Hymenoptera, mostly black ants, consumed is significantly $(P<0.01)$

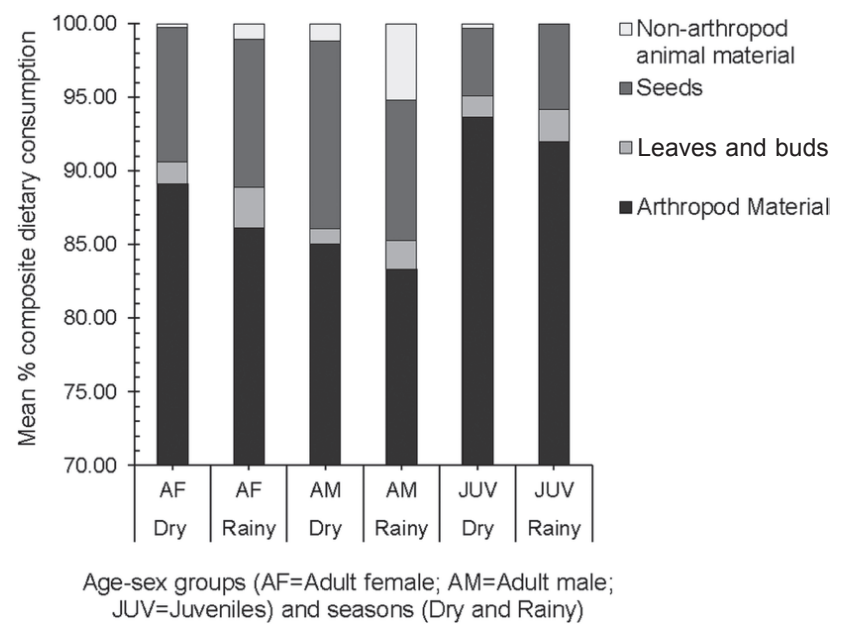

Figure 1. Mean percent composite dietary consumption in Agama agama by age-sex groups and seasons, assessed from analysis of 1453 sets of fecal pellets ( 3 to 5 pellets $=$ a set) from northern Nigeria, during June 2015 to May 2017. Note: In addition to statistically significant dietary differences amongst age-sex classes, there were also major differences in prey taxa consumed (see text).

affected by lizard class, months, seasons, and sites, but yearly differences had only marginal effect at $P=0.06$. Similar results for Diptera, Blattodea (Suborder Isoptera, termites), Orthoptera, Blattodea (Suborder Blattaria, cockroaches), Lepidoptera, melon and other dicot seeds were also significant at $P<0.001$. Leathery egg material and fragments of non-arthropod animal fibers separately are significantly affected by lizard class, year, site and season. Five factor MANOVA for effects of lizard classes, months, seasons, year, and sites on the mean percent composite fecal contents of the lizards (Table 4), including the interactions Lizard*Season* Lizard*Year were significant $(P<0.01)$.

\section{Discussion}

\section{Lizard Age-Sex Class Versus Food Items}

The age-sex classes of the Agama agama were created to explore the differences in the 
diets of the lizards that had been observed foraging. For example, neither females nor young and juveniles were seen to pursue large roaches (Periplanata americana Linnaeus, 1758); however, they did capture the smaller German roaches, Blattella germanica Linnaeus, 1767. Mature males were not found near flowers, whereas females and young and juveniles were; these observations suggest that food resources are partitioned among the age-sex classes. Similar observations have been reported for Agama agama and other lizards before (e.g., Akani et al. 2013). Angelici et al. (1997) attributed the feeding differences in age classes of Lacerta bilineata to ontogenetic change; thus, with juvenile western green lizards mainly select orthopterans, spiders, and Rhynchota, and then switch to beetles and isopods on maturation. Angelici et al. (1997) further suggested that age classes may inhabit different microhabitats that harbor different prey items which the lizards consume. Alternately, it is possible that members of the age classes partition their habitats to avoid intraspecific interference competition. This explanation is partly relevant to the present study, because adult males tended to forage on vertical surfaces walls, boulders or trees, whereas juveniles and young primarily seem to forage on the ground, only ascending when adult males were absent.

The Discriminant Analysis revealed that all of the individual diet items contributed $60 \%(N$ Proportion Correct $=60.2 \%$ ) to lizard class separation. Females have the lowest proportion of correctly classified lizards (51\% proportion correct or 250 of 483 ); this probably indicates that they have a wider dietary overlap than does either of the two other classes. Cluster analysis of the same individual food items showed that all of the 1451 lizards had less than half (46.3\%) of their total foods in common; this value is much lower than that $(76.1 \%)$ obtained in a cluster analysis of four composite foods. This demonstrates resource partioning among different lizard age-sex classes is more evident with the lower taxonomic identification of the prey, and conversely, the separation of classes is obscured when prey taxa are pooled into composite dietary items.

\section{Frequencies of Dietary Items}

The predominance of dipteran prey in fecal matter might suggest the abundance of the

Table 4. General linear model MANOVA showing the effects of lizard classes (adult female, adult male, young and juveniles); months (June 2015-May 2017); season (dry and rainy); year (2015, 2016, 2017); and site (JanGuza, Rimin Gata, Gezawa and Zakirai) on mean percent composite food items determined from analysis of 1453 sets of fecal samples.

\begin{tabular}{lccccc}
\hline & & \multicolumn{3}{c}{ Wilks' $^{\prime}$} \\
\cline { 2 - 6 } & & & \multicolumn{1}{c}{$\boldsymbol{D F}$} \\
\cline { 4 - 6 } Criterion & $\begin{array}{c}\text { Test } \\
\text { Statistic }\end{array}$ & $\boldsymbol{F}$ & $\boldsymbol{N}$ & Denom & $\boldsymbol{p}$ \\
Lizard & 0.91236 & 17.000 & 8 & 2898 & 0.000 \\
\hline Month & 0.79255 & 7.848 & 44 & 5511 & 0.000 \\
Season & 0.94043 & 22.960 & 4 & 1450 & 0.000 \\
Year & 0.98842 & 2.117 & 8 & 2898 & 0.031 \\
Site & 0.96768 & 3.989 & 12 & 3831 & 0.000 \\
Lizard*Season & 0.94568 & 10.224 & 8 & 2888 & 0.000 \\
Lizard*Year & 0.97748 & 2.058 & 16 & 4399 & 0.008 \\
\hline
\end{tabular}


insects in what is a degraded, semi-arid environment. This might imply that other arthropod resources were limited in the study sites and/or that there was an abundance of flies near homesteads. I suspect that the latter probably accounts for the high frequency of dipterans in the lizard diet. Gonçalves et al. (2013) and Leaché et al. (2006) described association of Agama agama with human settlements. Lizards living near humans benefit from the availability of dipteran insects-i.e., especially common flies and mosquitoes-which abound near human habitation and decline further away in more remote areas.

The frequency of water melon seeds (Citrullus lanatus) in fecal samples exceeded that of other dicot seeds, as well as the frequency of each of five arthropod orders-viz., Coleoptera, Hemiptera, Lepidoptera, Blattodea (Suborder Blatteria, cockroaches), and Odonata. This suggests that Agama agama is opportunistic and that the lizard consumes any nutritious items in its track (Barnett and Emms 2005, Hardy and Crnkovic 2006, Vasconcelos et al. 2014). The melon seeds probably came from fruits that were damaged in the course of handling and transportation or simply discarded. The minor frequency $(0.6 \%)$ of unidentified arthropod materials is reported without further comment.

\section{Lizard Age-Sex Class: Relative and Intraclass Variations in Dietary Selection}

Young and juvenile Agama agama may consume proportionally more dipterans because of the abundance of the latter and the ease with which dipterans can be caught. Gupta (1982), however, attributed the relatively low representation of dipteran insects in the diet of Agama agama to the ability of the prey to fly and evade capture - a hypothesis not supported by my data. I attribute the high frequency of dipteran prey in the diet of Agama agama as reflection of the paucity of other arthropod food sources in the study areas, in contrast to what would be available in richer, less degraded, savannah fields or, cleared forest lands with more insects. The higher coefficient of variation associated with hymenopteran and blattodean (Suborder Blatteria, cockroaches) prey suggests that some of the lizards ate them, while some lizards preferred to consume other taxa as prey.

In most other dietary studies of Agama agama, arthropod prey items were also important (Pauwels et al. 2004, Hardy and Crnkovic 2006). The arthropod taxon that ranks the highest seems to depend on the locality and/or opportunistic feeding; thus, dipterans predominate in the present study, whereas isopods and coleopterans rank highly in West Africa (Akani et al. 2013) and Blattodea (Suborder Isoptera, termites) in arid central Kenya (Hardy and Crnkovic 2006). All other, non-arthropod diet groups contributed less than $16 \%$ to the diets of each of the lizard classes. The balance of the diets was composed of seeds of melon and other dicots, with a $5-11 \%$ overall relative food intake. Clearly, Agama agama is primarily an insectivorous, commensal reptile.

The non-arthropod animal fibers in fecal pellets constituted about $3 \%$ of the mean relative amounts for adult males, in contrast to the scant $0.5 \%$ for adult females and young and juveniles; nevertheless, their presence is a surprise because only two incidents of cannibalism were recorded in the $2 \mathrm{yr}$ of the present study. People in the communities at the study sites have noticed cannibalism and vertebrate predation by Agama agama, and the behavior has also been reported in the literature (Harris 1964, Vasconcelos et al. 2014). The occurrence of the non-arthropod animal material coincided with the peak rainy season, a time when snails were available. Although Agama agama has not been observed eating snails and small frogs, it cannot be ruled out. There was also a scanty supply of small vertebrate prey items, such as local skinks and lacertids, which have not been identified to species because they were rare at the study sites, and I lacked suitable live traps to collect them for identification. Field observations document that Agama agama is strictly a predator that never has been seen to eat a dead arthropod or 
feed on the carcass of either a small vertebrate or that of a larger animal. Paradoxically, the lizards relished cooked food in human discards, exhibiting their commensal habits while retaining their predatory behavior.

Adult males did not consume many flowers (mean of $0.02 \%$ ) relative to other food items. There was also a large value of 1497.18 coefficient of variation for this item, indicating that only a few members of the adult male class ate flowers. However, in one Ghanaian study (Yeboah 1982), it was the male that consumed more flowers than the other age-sex classes.

\section{Relative Dietary Share Amongst Age-Sex Classes Versus Seasons}

I did not expect that the intake of arthropods in the dry season would exceed that of the rainy season, given that a greater variety of arthropods, as well as fresh plant material, is available in the rainy season. Leaves and buds were eaten in small amounts, but probably enough to compensate for the reduced intake of the arthropods. Chapman and Chapman (1964) documented the intake of plant material by Agama agama, but this occurred during the dry season. The relatively high value of seeds in the lizards diets toward the end of the rains and the beginning of the dry season probably compensated for the 5\% lower intake of arthropods during the rains. Because dipterans and hymenopterans abound throughout the year, it is conceivable that the lizards would avail themselves of another variety of protein in the form of seeds, which are abundant early in the dry season-perhaps evidencing dietary opportunism.

\section{Utility of Fecal Analysis for Dietary Description}

The work of Caputo and Vogt (2008) addressed the reliability of fecal analysis; they advocate that only an integrated analysis of both stomach and fecal material would provide a comprehensive profile of the diet of the chelid turtle Rhinemys rufipes Spix, 1824. Likewise,
Pincheira-Donoso (2008) argued that soft-bodied prey items are not well represented in fecal samples. In contrast to the opinions of the latter researchers, two others argued that fecal pellet analysis is sufficient to describe the diet of Agama (Akani et al. 2013) and that of Lacerta bilineata Daudin, 1802 (Angelici et al. 1997); however, Angelici et al. (1997) mentioned some cautionary concerns.

The fungus Sclerotinia scleritiorum (Lib.) de Bary (1884) grows especially well on injured plant leaves and damaged berries such as tomatoes. It can be found on weeded, but still moist herbs, on some legume crop plants, as well as on discarded vegetable materials. My field observations indicate that adult female Agama agama, and young and juvenile lizards relished this food and ate it until supplies were exhausted. However, I did not identify, with any level of certainty, the residue of this, non-sporulating white mold; thus, I assume the mold was thoroughly digested, leaving no identifiable traces in the fecal pellets. Alternately, of course, the absence of fungal mycelia might indicate the absence of $S$. scleritiorum in the habitat of the lizard. Because the non-arthropod diet of the lizards constituted less than $16 \%$ (chiefly seeds) of all dietary components, fungal food items would be quantitatively unimportant. Nevertheless, the observation emphasizes the importance of an integrated approach-in this case, fecal analysis and field surveillance-to characterize the diet of Agama agama. The advantage of fecal analysis is that it obviates unnecessary handling of the lizard or the need to euthanize it. The disadvantage of the method is the length of time it takes to collect fecal samples that are associated to specific individuals and age-sex classes of the lizard.

\section{Acknowledgments}

I am indebted to Mr. Yakubu Otaro, Senior Technical Officer, Graduate Research Laboratory, Biological Sciences Department, Bayero University Kano, Nigeria, for providing some equipment and supplies for this project. 


\section{References}

Akani, G. C., F. Petrozzi, L. Rugiero, G. H. Segniagbeto, and L. Luiselli. 2013. Effects of rainfall and geography on the comparative diets of eight rainbow lizard populations across Togo, Benin and Nigeria (West Africa). Amphibia-Reptilia 34: 185-192.

Angelici, F. M., L. Luiselli, and L. Rugiero. 1997. Food habits of the green lizard, Lacerta bilineata, in central Italy and a reliability test of fecal pellet analysis. Italian Journal of Zoology 64: 267-272.

Avery, R. A. 1971. Estimates of food consumption by lizard Lacerta vivipara Jacquin. Journal of Animal Ecology 40: 351-365.

Barnett, L. and C. Emms. 2005. Common Reptiles of the Gambia. Hailsham East Sussex. Rare Publishers. 24 pp.

Caputo, F. P. and R. C. Vogt. 2008. Stomach flushing vs. fecal analysis: the example of Phrynops rufipes (Testudines: Chelidae). Copeia 2008: 301-305.

Chapman, B. M. and R. F. Chapman. 1964. Observations on the biology of the lizard Agama agama in Ghana. Proceedings of Zoological Society London 143: 121132.

Delsinne, T., O. S. G. Pauwels, J. P. V. Weghe, and Y. Braet. 2015. Predation on Dorylus army ants (Hymenoptera: Formicidae: Dorylinae) by Agama agama (Squamata: Agamidae) in Gabon. Bulletin de la Société Royale Belge d'Entomologie 151: 147-149.

Enge, K. M., K. L. Krysko, and B. L. Talley. 2004. Distribution and ecology of the introduced African Rainbow lizard, Agama agama africana (Sauria: Agamidae), in Florida. Florida Scientist 67: 303-310.

Gonçalves, D. V., F. Álvares, and J. C. Brito. 2013. Data on the distribution of herpetofauna of southern Niger with comments on Termit and Tin Toumma National Nature Reserve. Boletín Asociación Herpetologica Española 24: 74-79.

Gonçalves, D. V., J. C. Brito, P. A. Crochet, P. Geniez, J. M. Padial, and D. J. Harris. 2012. Phylogeny of North African Agama lizards (Reptilia: Agamidae) and the role of the Sahara Desert in vertebrate speciation. Molecular Phylogenetics and Evolution 64: 582-591.

Gupta, J. C. 1982. Evaluation of Agama agama (Squamata, Agamidae) as a natural control agent of insect pests. Zeitschrift für Angewandte Entomologie 93: 397-402.

Hardy, L. M. and A. C. Crnkovic. 2006. Diet of amphibians and reptiles from Engare Ondare River Region of central Kenya, during the dry season. African Journal of Herpetology 55: 143-159.
Harris, V. A. 1964. The Life of the Rainbow Lizard. London. Hutchinson Tropical Monographs, Hutchinson and Company. 174pp.

Kissling, W. D., A. Blach-Overgaard, R. E. Zwaan, and P. Wagner. 2016. Historical colonization and dispersal limitation supplement climate and topography in shaping species richness of African lizards (Reptilia: Agaminae). Scientific Reports 6: 34014.

Leaché, A. D., M. O. Rödel, C. W. Linkem, R. E. Diaz, A. Hillers, and K. M. Fujita. 2006. Biodiversity in a forest island: reptiles and amphibians of the West African Togo Hills. Amphibian and Reptile Conservation 4: 2245.

Leaché, A. D., J. A. Grummer, M. Miller, S. Krishnan, M. K. Fujita, W. Böhme, A. Schmitz, M. Lebreton, I. Ineich, L. Chirio, C. Ofori-Boateng., E. A. Eniang, E. Greenbaum, M. O. Rödel, and P. Wagner. 2017. Bayesian inference of species diffusion in the West African Agama agama species group (Reptilia, Agamidae). Systematics and Biodiversity 15: 192-203.

Lopes, M. S., R. S. Bovendorp, G. J. Moraes, A. R. Percequillo, and J. Bertoluci. 2017. Diversity of ants and mites in the diet of the Brazilian frog Chiasmocleis leucosticta (Anura: Microhylidae). Biota Neotropica 17: e20170323.

López, P., J. Martin, and A. Salvador. 1991. Diet selection by the Amphisbaenian Blanus cinereus. Herpetologica 47: $210-218$.

Luiselli, L., G. C. Akani, N. Ebere, and V. Pérez-Mellado. 2011. Stomach flushing affects survival/emigration in wild lizards: a study case with rainbow lizards (Agama agama) in Nigeria. Amphibia-Reptilia 32: 253-260.

Marshall, A. J. and R. Hooks. 1960. The breeding biology of equatorial vertebrates: reproduction of the lizard Agama agama lionotus Boulenger at lat. 0.01' N. Proceedings of the Zoological Society of London 134: 197-205.

Mediannikov, O., S. Trape, and J. F. Trape. 2012. A molecular study of the genus Agama (Squamata: Agamidae) in West Africa, with description of two new species and a review of the taxonomy, geographic distribution, and ecology of currently recognized species. Russian Journal of Herpetology 19: 115-142.

Pauwels, O. S. G., D. Gramentz, and A. K. Toham. 2004. Agama agama (Rock-headed Rock Agama). Nocturnal activity. Herpetological Review 35: 164-165.

Pérez-Mellado, V. and C. Corti. 1993. Dietary adaptations and herbivory in lacertid lizards of the genus Podarcis 
from Western Mediterranean islands (Reptilia: Sauria). Bonner Zoologische Beiträge 44: 193-220.

Pérez-Mellado, V., A. Pérez-Cembranos, M. Garrido, L. Luiselli, and C. Corti. 2011. Using fecal samples in lizard dietary studies. Amphibia-Reptilia 32: 1-7.

Pincheira-Donoso, D. 2008. Testing the accuracy of fecal based analyses in studies of trophic ecology of lizards. Copeia 2008: 322-325.

Rabiu, S. and R. K. Rose. 1997. A quantitative study of diet in three species of rodents in natural and irrigated savanna fields. Acta Theriologica 42: 55-70.

Sáez, E. and A. Traveset. 1995. Fruit and nectar feeding by Podarcis lilfordi (Lacertidae) on Cabrera Archipelago (Balearic Islands). Herpetological Review 26: 121-123.
Vasconcelos, R., E. Lopes, and B. H. Martins. 2014. Agama agama: a charter tourist in the Cape Verde Islands? African Journal of Herpetology 63: 34-46.

Wagner, P., F. Glaw, K. Glaw, and W. Böhme. 2009. Studies on African Agama IV: first record of Agama agama (Sauria: Agamidae) from Madagascar and identity of the alien population on Grande Comore Island. Herpetological Notes 2: 73-77.

Yeboah, S. 1982. Observations on territory of the rainbow lizard, Agama agama. African Journal of Ecology 20: $187-192$.

Editor: Claudia Koch 